\title{
POLÍTICA FORESTAL Y PRODUCCIÓN DE LOS MONTES PÚBLICOS ESPAÑOLES. UNA VISIÓN DE CONJUNTO, 1861-1933*
}

\author{
GRUPO DE ESTUDIOS DE HISTORIA RURAL **
}

\section{RESUMEN}

Una de las consecuencias de las transformaciones de la propiedad de la tierra en España, durante el siglo xIx, fue la constitución de un extenso patrimonio forestal público (6,6 millones de hectáreas), que pasó a depender de la administración central y que se conserva hoy casi en su totalidad. En este artículo se ofrece una visión de conjunto de las producciones y de la gestión de los montes públicos. La intervención del Estado se ha dividido en cuatro etapas y, considerando los resultados más que los objetivos iniciales, destacan dos conclusiones. Primera: por sus características, los montes públicos no eran adecuados para que los gobiernos los utilizaran con el fin de dirigir el rumbo de la economía forestal nacional. Segunda: la administración central aplicó, no una, sino varias políticas forestales, atendiendo a los cambios en los mercados y a las diferentes circunstancias económicas, sociales y ecológicas de las comarcas donde se encontraban los montes.

$N$ de E.: Fecha de recepción del artículo: julio, 2000.

Fecha de aprobación por el Consejo de Redacción: octubre, 2002.

* Este artículo recoge una parte de los resultados del proyecto de investigación Protección versus producción de los montes públicos españoles, 1860-1979, financiado por el Instituto para la Conservación de la Naturaleza (ICONA). Agradecemos los comentarios de tres evaluadorres de la Revista, que nos han servido para mejorar el texto original.

* El Grupo de Estudios de Historia Rural (GEHR, en adelante) está formado por Domingo Gallego Martínez, José Ignacio Jiménez Blanco, José Antonio Sebastián Amarilla, Juan Francisco Zambrana Pineda y Santiago Zapata Blanco. 


\section{ABSTRACT}

One of the consequences of transformations in Spanish land properties in the 19th century was the constitution of an extensive (6.6 million hectares) public forest patrimony - still kept- dependent on the Central Administration. In this article, an overview of the main features, as well as the management and production forms of such a patrimony, is presented. State intervention is divided into four stages and, considering their results rather than their initial goals, two main conclusions are reached. First, given their characteristics, public forests were not adequate for the government to be able to lead this part of the forest national economy. Second, the central administration applied not one but several public forest policies, according to changes in the markets and to the economic situation, and social and ecological conditions where forests were found.

JEL Classification: N53, N54, Q23

\section{INTRODUCCIÓN}

El objeto de este trabajo es realizar un análisis global de la gestión de los montes públicos efectuada por la administración forestal española durante la segunda mitad del siglo $\mathrm{xx}$ y el primer tercio del $\mathrm{xX}^{1}$. Prestaremos más atención, no obstante, al periodo situado entre 1900 y 1933 que a los años precedentes, y ello por dos motivos. El primero estriba en que, desde la desamortización de Madoz hasta mediados de la década de 1870 , la actividad de la administración se concentró en el proceso de privatización de la titularidad del monte $-\mathrm{y}$, a la vez, de creación y conservación de un patrimonio forestal público-, asunto al que ya hemos dedicado otro artículo - GEHR (1994)—, el cual, en parte, tiene aquí continuación. El segundo es la falta de información estadística seriada para las dos últimas décadas del siglo XIX, cuando despegó la gestión de dicho patrimonio y comenzaron a ponerse a prueba los proyectos forestales de la administración, al aplicarse a la compleja y variada realidad del mundo rural español.

Partimos de la hipótesis de que, para caracterizar la gestión de los montes públicos, es preciso evaluar los comportamientos efectivos de la administración central y no sólo las bases legales y programáticas que respaldaban sus decisiones. Un importante correlato de la misma consiste en que, al estar los montes públicos dispersos por ámbitos muy variados,

${ }^{1}$ En el Apéndice se explica el significado de los principales términos forestales empleados en el artículo. 
tanto desde el punto de vista natural como social, resulta preciso acompañar el análisis general con otro más pormenorizado, al menos de carácter regional, que permita captar con detalle las distintas formas como se fue plasmando la política forestal. Aunque hemos realizado ambos, en este artículo nos centraremos, por motivos de espacio, en el primero, si bien haremos referencia a algunos aspectos que proceden de los resultados del segundo.

Entre los numerosos artículos y libros que se han publicado en los últimos años sobre la historia forestal contemporánea de España, ha sido de especial utilidad, para este trabajo, la recopilación efectuada de las estadísticas oficiales de superficies y producciones ${ }^{2}$. Éstas, amén de aportar un voluminoso conjunto de cifras que gozan de un aceptable grado de veracidad, constituyen el reflejo de los distintos papeles que hubo de representar la administración central, al ejercer sus funciones en entornos sociales y ecológicos diferentes. Debe considerarse que sus cifras se asemejan, más que a las procedentes de unas estadísticas en sentido estricto, a las provenientes de las cuentas de explotación de una gran empresa forestal que poseyese un conocimiento y un control muy dispares de los distintos componentes de su patrimonio. El que la gestión fuera principalmente indirecta -la realización efectiva de los aprovechamientos la efectuaban particulares $y$, en ocasiones, recaía en órganos administrativos locales o en empresas privadas-, y el que las pautas por las que se regía fuesen diversas, otorga a estos datos de producción una enorme capacidad de mostrar las distintas formas mediante las que se conectaban las acciones de la administración central y las de los grupos sociales que pugnaban por el acceso al monte público en cada territorio.

Dicha documentación, junto con las propuestas incluidas en algunas panorámicas generales y los testimonios e hipótesis que contienen numerosos estudios realizados para espacios más reducidos y con fuentes de origen local y provincial ${ }^{3}$, nos han permitido perfilar algunas cuestiones, las cuales adelantamos aquí aunque sin acompañarlas del preciso soporte

${ }^{2}$ Nos referimos a GEHR (1991, cuadros 15 a 19 y pp. 62-79, donde se hace la crítica de fuentes de las estadísticas forestales).

${ }^{3}$ Los trabajos de contenido general, relativos a toda España, son los de Mangas (1984), Sanz (1985) y (1986), Jiménez Blanco (1991a), (1991b) y (1994), Gómez Mendoza (1992), López Estudillo (1992) y Balboa (1999). Y una muestra de estudios monográficos de espacios más reducidos, ordenados por el año de su publicación, podría ser la siguiente: Mangas (1981), Jiménez Blanco (1986, pp. 338-427), Zapata (1986a, pp. 441-591), Balboa (1990), Montiel (1990), (1992) y (1995), Artiaga y Balboa (1992), Cobo, Cruz y González de Molina (1992a) y (1992b), Iriarte (1992), (1995) y (1997), Moreno (1994), Manuel Valdés (1996), Araque (1997), Sabio (1997), Sala (1997) y (1998b) y Linares (2001). 
analítico. A nuestro parecer, los diversos modos de gestión de los montes públicos que se fueron afianzando, durante el período considerado, en cada territorio y en cada tipo de monte, respondieron más al papel que hubo de asumir el sector público, en pugna permanente con los distintos grupos sociales que competían por el control de los aprovechamientos forestales, que a los designios exclusivos de una legislación y de unos principios generales; éstos tendieron a diluirse, más o menos según los casos, a la hora de afrontar las múltiples realidades concretas a las que pretendieron aplicarse. Así, la política forestal que efectivamente se llevó a cabo, como la política de comercio exterior, o la financiera, o la de orden público, fue resultado, en última instancia, de la compleja articulación de los intereses sociales en juego. En una sociedad poco homogénea, como la española - -especialmente, en las zonas rurales-, con equilibrios sociales muy dispares de unas comarcas y regiones a otras, resultaba poco viable la puesta en práctica de una política forestal uniforme, por lo que, en la realidad, lo que solemos hallar los investigadores son unas formas de gestión del monte público muy adaptadas a las condiciones locales y a las variaciones que en éstas tuvieron lugar, rompiéndose tal dinámica sólo cuando grupos externos a la comunidad rural aspiraban también a controlar el monte público.

No obstante, en las páginas que siguen, nos limitaremos a presentar una visión general de las características, formas de gestión y producciones de los montes públicos, haciendo hincapié en los aspectos cronológicos de la política forestal, a fin de acercarnos a lo que, desde la lógica argumental, ha de ir primero: el marco que permita comprender adecuadamente la acción del sector público en cada una de las circunstancias a las que tuvo que enfrentarse.

\section{LOS MONTES PÚBLICOS EN EL CONJUNTOO DE LOS MONTES}

La estimación que figura en el cuadro 1 nos aproxima a la capacidad productiva imputable a los montes públicos, dentro del subsector forestal español, al final del periodo estudiado ${ }^{4}$.

4 Somos conscientes de que dicha estimación es muy burda, al menos por tres motivos. Primero, porque utilizamos el año 1946-1947, situado fuera de la época que pretendemos analizar. Segundo, porque, en el año citado, aún no se disponía de una cuantificación veraz de las producciones de los montes de particulares. $\mathrm{Y}$, tercero, porque la producción de 


\section{CUADRO 1}

Producción de los montes públicos, de los de utilidad pública $y$ de los dependientes de Hacienda, en proporción a la del conjunto de los montes (España, 1946-1947) *

\begin{tabular}{lrrrrrrr}
\hline & Madera & Leña & Pastos & Esparto & Resina & Corcho & Total \\
\hline Total montes........................ & 100,0 & 100,0 & 100,0 & 100,0 & 100,0 & 100,0 & 100,0 \\
Total monte público ** .......... & 22,2 & 42,3 & 50,0 & 65,1 & 61,0 & 9,4 & 39,4 \\
Montes de utilidad pública...... & 21,2 & 32,0 & 29,0 & 39,5 & 59,1 & 7,9 & 27,4 \\
Montes de Hacienda ** .......... & 0,9 & 10,3 & 21,0 & 25,5 & 1,9 & 1,5 & 12,0 \\
\hline
\end{tabular}

* Los cálculos correspondientes a los esquilmos se han efectuado sobre la producción de cada uno en términos físicos. Los concernientes a la producción total, sobre la suma de los valores a precios corrientes de los respectivos productos.

** Estimaciones según la relación existente entre las producciones de los montes de utilidad pública y los de Hacienda hacia 1920.

Fuentes: Ministerio de Agricultura (1949, pp. 83-88), para el total de los montes y para los de utilidad pública en 1946-1947; Biblioteca del Ministerio de Hacienda, libros 23.469 y 23.470, para los montes de Hacienda en 1920-1921; y GEHR (1991, cuadro 19), para los montes de utilidad pública en 1919-1920.

Se aprecia que la suma de las producciones de los montes públicos representaba cerca del 40 por 100 de la producción forestal total, expresadas ambas en valor ${ }^{5}$. En cuanto a los distintos aprovechamientos, medidos en términos físicos, resulta que la resina, el esparto y los pastos de los montes públicos suponían la mitad o más de las respectivas producciones totales de los montes, situándose la leña en torno al 40 por $100 \mathrm{y}$, a un nivel bastante inferior, la madera - alrededor del 22 por $100-y$, sobre todo, el corcho, con menos del 10 por 100 .

los montes de Hacienda - adviértase el evidente anacronismo que supone utilizar esta denominación en 1946-1947 cuando, desde 1926 y tras un quinquenio de administración por el Ministerio de Fomento, tales montes pasaron a constituir los de libre disposición de los pueblos- la hemos obtenido a partir de las proporciones existentes, hacia 1920, entre las producciones de éstos y las de los montes de utilidad pública.

"Este porcentaje quedaría reducido al 15 por 100 si en la citada producción total se hubieran incluido las praderas naturales, cuyo valor supera al de todos los demás esquilmos juntos. No obstante, vamos a prescindir en este artículo, que sólo se ocupa de los montes públicos, de las praderas naturales, ya que la totalidad de este aprovechamiento se realiza en los montes de particulares. En cambio, sí hemos tenido en cuenta a las susodichas praderas en un trabajo, que se publicará próximamente, sobre la producción forestal de todos los montes españoles (públicos y privados) entre mediados de la década de 1940 y finales de la de 1970. 
Estos porcentajes evidencian que las producciones de los montes públicos ocupaban un lugar importante en la economía forestal del país. Ahora bien, si consideramos que una de las principales finalidades de dichos espacios era la de servir de instrumento de la política forestal de la administración central, lo que entonces llama la atención, en términos comparativos, es su insuficiencia. En efecto, el grado de influencia sobre el subsector que permitían ejercer era muy desigual, según tipos de producción, vistas las cantidades obtenidas de cada producto, y según ámbitos geográficos, dado que tales montes se hallaban muy irregularmente repartidos por el territorio nacional ${ }^{6}$.

Al respecto, cabe afirmar que la producción de madera -el aprovechamiento forestal por excelencia - del conjunto de los montes públicos era relativamente escasa, aunque no tanto como la de corcho, mientras que las de resina y esparto resultaban más destacables, así como las de pastos y leñas. No obstante, debe advertirse que los tres primeros esquilmos citados - los estrictamente forestales - procedían de una extensión muy reducida de los montes públicos. La resina y la madera salían, en su mayor parte, de una pequeña porción del monte público ubicado en el centro y en el norte del país, y lo propio acaecía, en el sur, con el corcho ${ }^{7}$.

En consecuencia, los rasgos comunes a muchos montes públicos consistían en ser poco maderables y en proporcionar pequeñas cantidades de resina, algo menos de esparto y nada de corcho, a la par que eran productores, sobre todo, de pastos y leñas. Puede entenderse, así, que el interés de la administración por controlar su uso se resintiese de sus escasas condiciones forestales, especialmente si a ello se añade el que, con tales características, constituían un espacio privilegiado para la sobrevivencia de aprovechamientos comunales $\mathrm{y}$ otras formas ancestrales de utilización de las áreas incultas.

En semejante contexto, era muy difícil para la administración poner en marcha y sostener, partiendo del monte público, una política beligerante de ordenación del subsector forestal, especialmente si ésta, como resultaba

${ }^{6}$ En cuanto a esto último, véase GEHR (1994, mapa 8).

7 Para 1946-1947 y sólo respecto de los montes de utilidad pública, los situados en siete provincias - Burgos, Ávila, Segovia, Soria, Valladolid, Cuenca y Guadalajara- proporcionaban el 83 por 100 de la producción de resina de aquéllos. Las mismas provincias más Navarra aportaban el 62 por 100 de la de madera. Por su parte, los radicados en Málaga y Cádiz, por sí solos, daban cuenta del 100 de la de corcho. Algo similar ocurría con el esparto en el sudeste, donde los montes de Albacete, Jaén, Granada, Almería y Murcia aportaban el 95 por 100 de su producción. 
ineludible, había de tener en cuenta, de una forma u otra, los complejos $\mathrm{y}$ variados intereses económicos y sociales a los que afectaba.

\section{LOS DISTINTOS TIPOS DE MONTE PÚBLICO}

En el cuadro 2 se mide el peso porcentual de cada esquilmo en el conjunto de la producción de cada tipo de monte público. Se observa, de un lado, que los montes gestionados por el Ministerio de Hacienda eran los más alejados de lo estrictamente forestal y los más vinculados a la actividad agrícola y ganadera, ya que los pastos y las roturaciones suponían algo más del 80 por 100 de su producción. De otro, los espacios administrados por los distritos eran los más representativos del monte público español. La elevada proporción de los pastos y el que la mayor parte de la leña fuese de monte bajo los asemejaba a los montes de Hacienda; sin embargo, la importancia relativa de sus producciones de madera — su-

\section{CUADRO 2}

Producciones de los distintos tipos de montes públicos, en porcentaje sobre la producción total de éstos valorada a precios corrientes (España, bacia 1920)

\begin{tabular}{|c|c|c|c|c|c|c|c|c|c|}
\hline Tipos de montes & Madera & Leña & Pastos & $\begin{array}{c}\text { Monta- } \\
\text { nera }\end{array}$ & Esparto & Resina & Corcho & $\begin{array}{l}\text { Rotura- } \\
\text { ciones }\end{array}$ & Total \\
\hline De Hacienda ${ }^{1} \ldots$ & 3,1 & 5,7 & 58,1 & 1,4 & 3,0 & 1,5 & 0,6 & 23,8 & 100,0 \\
\hline De los distritos ${ }^{2} \ldots \ldots \ldots \ldots$ & 25,9 & 9,4 & 44,7 & 1,0 & 2,6 & 12,5 & 0,4 & 0,9 & 100,0 \\
\hline Ordenados ${ }^{2} \ldots \ldots \ldots \ldots \ldots$ & 40,3 & 3,0 & 10,2 & 3,2 & - & 37,6 & 3,6 & 0,5 & 100,0 \\
\hline Repoblados $^{2} \ldots \ldots \ldots \ldots$ & 19,4 & 14,1 & 46,4 & - & 10,9 & - & - & 0,8 & 100,0 \\
\hline De utilidad pública ${ }^{3} \ldots$ & 30,2 & 7,6 & 34,3 & 1,6 & 2,0 & 19,9 & 1,4 & 0,7 & 100,0 \\
\hline Total monte público ${ }^{4} \ldots$ & 22,5 & 7,1 & 42,1 & 1,6 & 2,3 & 14,7 & $\overrightarrow{1,1}$ & 7,7 & 100,0 \\
\hline
\end{tabular}
plantas..

* Los porcentajes no suman 100 por faltar otros aprovechamientos como caza, canteras,

1 Año forestal 1920-1921.

2 Año forestal 1919-1920.

${ }^{3}$ Los porcentajes resultan de sumar las producciones de distritos, ordenaciones y repoblaciones.

${ }^{4}$ Los porcentajes resultan de sumar las producciones de los montes de Hacienda (año 1920-1921) y las de los de utilidad pública (año 1919-1920).

FUENTES: Los cálculos se han realizado sobre Biblioteca del Ministerio de Hacienda, libros 23.469 y 23.470, y Dirección General de Agricultura, Minas y Montes (1922, pp. 56-57, estado 1). 
perior al 25 por 100 - de resina y de leña de monte alto los aproximaba a las características de los montes dependientes de la Inspección de Ordenaciones, los «más forestales» de todos, si se nos permite la expresión.

En los montes ordenados, en efecto, la madera representaba el 40 por 100 del valor de la producción, a la par que casi todos los demás aprovechamientos presentes con alguna relevancia, como la resina, el corcho y la leña de monte alto, eran típicamente forestales. Si bien en ellos aún tenía cabida el pastoreo en una proporción no desdeñable, se trataba, con toda probabilidad, de un esquilmo residual y en declive.

Los montes repoblados, por último, eran, ante todo, espacios forestales en proceso de constitución, de los que sólo se obtenían ciertas producciones de modo subsidiario. Parece claro, además, que, en el período observado, la reforestación atendía, más que a la creación de nuevas superficies productivas, a incrementar la función protectora del arbolado, especialmente, a la fijación del suelo.

De lo dicho parece desprenderse que la administración central no contaba con los montes de Hacienda - muchos de ellos aún enajenables, no se olvide - para desarrollar y aplicar su política forestal, que se concentraba en los montes ordenados y en repoblación ${ }^{8}$. Entre unos y otros, se situaba la mayor parte de los terrenos públicos dependientes de los distritos, en los cuales coexistían superficies de difícil control, orientadas a usos ganaderos y al abastecimiento doméstico de combustible, junto a otras en las que iba en aumento el dirigismo de la administración $\multimap$ de los grupos sociales apoyados por ésta- en la obtención de sus aprovechamientos.

Así, cabe concluir que la intervención del Estado tuvo muy diversa intensidad y diferentes objetivos, según el tipo de monte público afectado, según las circunstancias del lugar donde éste se encontrara y, también, según el momento en que se aplicara, como se verá a continuación.

\section{LAS ESTRATEGIAS DE GESTIÓN DE LOS MONTES PÚBLICOS: SU EVOLUCIÓN TEMPORAL}

A pesar de las recientes avances habidos, nuestro conocimiento sobre la economía forestal española de la segunda mitad del siglo XIX y primer tercio del $\mathrm{xx}$ dista aún de ser completo. Por ello, la división cronológica

${ }^{8}$ En Ministerio de Fomento (1912, pp. 265-456), en el apartado dedicado al Servicio de Montes, se describe con claridad, y con refrendo estadístico, la función directamente productiva de las ordenaciones y protectora de las repoblaciones. 
en cuatro etapas que ofrecemos a continuación debe considerarse sólo como una hipótesis provisional de la cambiante actuación del Estado, en su papel de gestor de los montes públicos durante los años estudiados.

La primera de dichas etapas la situamos entre 1855 y 1875 . Empezaría, por consiguiente, con la desamortización de Madoz y concluiría con el advenimiento de la Restauración, distinguiéndose la intervención del Estado, en estas dos décadas, por dedicarse casi en exclusiva a la tutela del proceso privatizador de los terrenos forestales - de los pertenecientes, en particular, a los pueblos- y a la creación y consolidación de un patrimonio forestal público en el contexto de nuevos derechos de propiedad, una de las expresiones genuinas del flamante sistema económico capitalista, que se imponía por doquier. La gestión propiamente dicha de ese patrimonio que se iba constituyendo quedó relegada a un lugar secundario.

Esta sintética caracterización, no obstante, necesita de algunas correcciones, para acercarse un poco más a lo que nos parece que, de verdad, sucedió.

Comencemos por los años que hemos elegido para delimitarla, 1855 y 1875. En el primero se promulgó la ley de desamortización general, que dio lugar a un rápido proceso de privatizaciones de la riqueza rústica en manos, de diverso modo, de los municipios o de los vecinos, gracias al cual se modificó, en poco tiempo, la titularidad de millones de hectáreas 9 . A la vez, mediante la aplicación de las condiciones de excepción establecidas en su artículo segundo, la mencionada ley contribuyó a la formación, o preservación parcial, de un patrimonio forestal público, que sería gestionado por la administración central.

Sin embargo, el citado proceso privatizador comenzó mucho antes de 1855 , por más que a partir de dicho año se acelerase y generalizase su ejecución ${ }^{10}$. $\mathrm{Y}$, asimismo, cabe considerar a las Ordenanzas de Montes de 1833 como un precedente de la intervención del Estado con el fin de preservar o constituir un patrimonio forestal público dependiente de la administración central.

${ }^{9}$ Aunque todas las desamortizaciones, y la de 1855 no fue una excepción, afectaron a la riqueza rústica y urbana de las instituciones que fueron expropiadas, aquí sólo nos referiremos a los terrenos rústicos. Sobre la cantidad de tierra privatizada a partir de la desamortización general de 1855, véase GEHR (1994, pp. 101-114).

${ }^{10}$ Las principales medidas, anteriores a dicha fecha, que facilitaron la privatización del usufructo o de la propiedad de los terrenos municipales o vecinales, fueron el Decreto de 4 de enero de 1813, el de 29 de junio de 1822 y el Real Decreto de 13 de mayo de 1837. Al réspecto, véase Jiménez Blanco (1996). 
No obstante, 1855 es, sin duda, un punto de inflexión en la historia de la España del siglo XIX -y no sólo de su historia agraria-, por lo que consideramos oportuno mantenerlo como fecha inicial, si no como principio de un proceso de privatización y de consolidación de un patrimonio forestal público, sí, desde luego, como un momento en que dicho proceso se intensifica y consolida ${ }^{11}$.

También 1875 es un punto de inflexión histórico — sobre todo en la historia política del país-, si bien han pesado más otros motivos a la hora de escogerlo como final de la primera etapa, como son la aplicación de planes de aprovechamiento forestal, redactados por los ingenieros de los distritos, a todos los montes públicos del país, a partir de 1873-1874, y el encargo de la vigilancia de los montes públicos a la Guardia Civil en 1876.

La gestión del monte público quedó, en esta primera etapa, en un segundo plano. Así nos lo parece. Pero es de justicia mencionar la especial atención legislativa que se le prestó, ya que, si prescindimos de las ordenanzas citadas más arriba, la primera ley de montes de la España contemporánea se promulgó en 1863 y puso las bases de la gestión estatal que se llevaría a cabo con posterioridad, durante un período muy largo, cercano al siglo.

La segunda etapa abarcaría de 1875 a 1900 . A diferencia de la anterior, en ésta - como en las sucesivas - la administración del patrimonio forestal público constituyó la principal actuación del Estado en el subsector forestal. En su transcurso, se comenzaron a definir las líneas maestras, más concretas, de dicha actuación —ordenaciones y repoblaciones-, aunque su aplicación fue muy escasa, y se pusieron en práctica nuevas formas de utilización y de control del monte público, mediante la generalización de los planes de aprovechamiento, con arreglo a la citada ley de 1863, y de la vigilancia por parte de la Guardia Civil.

${ }^{11}$ Cuando hablamos de un proceso de privatización y de formación o consolidación de un patrimonio forestal público, no queremos decir que el Estado tuviera un plan, al respecto, que se fuese cumpliendo más o menos meticulosamente. Por lo que parece, sucedió algo muy distinto: el Estado, encarnado en los gobernantes de cada momento, no elaboró ningún plan concreto, y actuó movido por objetivos políticos -como el de asegurar en el poder a determinados grupos sociales- y por la presión, de distinta naturaleza, que ejercían la evolución de los mercados y la actitud de quienes se veían perjudicados o beneficiados con las medidas que se ponian en práctica. Y todo ello aconteció en un ambiente contradictorio y conflictivo, dentro, incluso, de la propia administración central, como lo prueban las modificaciones de la normativa sobre los terrenos que debían exceptuarse de la desamortización y la diferente aplicación que, de tal normativa, hicieron los funcionarios de Hacienda o algunos ingenieros de montes adscritos al Ministerio de Fomento. 
El verdadero alcance de los mencionados planes y de la labor de policía realizada por el instituto armado aludido aún está por averiguar ${ }^{12}$. Sin embargo, por poco y desigualmente que los unos planificaran y el otro vigilara, no cabe duda de que en este período se produjo un cambio cualitativo trascendental en el uso del monte público, que vino a romper con hábitos seculares, especialmente con la casi nula injerencia de la administración central en la forma de realizar los aprovechamientos y con la reducida capacidad de vigilancia de una guardería forestal integrada por diversos cuerpos poco especializados, con funciones heterogéneas y escasos efectivos ${ }^{13}$.

La fecha de 1900 , en que concluye esta segunda etapa, queda justificada por la importante reorganización administrativa que trajo consigo la ley de presupuestos para el año 1897 y que se haría efectiva en 1901, con la publicación del catálogo de montes de utilidad pública - cuya gestión se encomendaba al Ministerio de Fomento- y el traspaso al Ministerio de Hacienda del resto de los montes públicos, aquellos que no alcanzaron la condición de utilidad pública.

La tercera etapa, que situamos entre 1900 y 1924, se caracterizaría, amén de por la ampliación y reforma de la legislación vigente, por el comienzo efectivo de las repoblaciones y, sobre todo, de las ordenaciones de montes públicos. Estas últimas contribuyeron de modo especial al avance de los aprovechamientos ordinarios, realizados mediante subastas, a costa de los vecinales, gratuitos o casi gratuitos, un asunto de la mayor importancia porque refleja los cambios que se estaban produciendo en el uso de la superficie forestal pública, los cuales, hasta entonces, parece que se habian introducido con relativa lentitud. Véanse, al respecto, los cuadros 3,4 y 5 .

Además de propiciar el aumento de los aprovechamientos ordinarios, las ordenaciones dieron lugar a una mejora de la productividad media por hectárea, como se desprende del cuadro 6 , en el que los porcentajes de

${ }^{12}$ Hacerse una idea de los efectos de los planes de aprovechamiento en los montes públicos durante el periodo 1881-1900, para el que no existen estadísticas de producción forestal, requiere una explotación detenida de la voluminosa - y riquísima - documentación relativa a los mismos que se custodia en el Archivo del Ministerio de Agricultura. Aunque todavía no hemos podido acometer esta enjundiosa labor, esperamos hacerlo próximamente. En cambio, sí hemos efectuado un primer análisis de las denuncias impuestas por la Guardia Civil en los montes públicos: GEHR (1999).

${ }^{13}$ Dicha transformación debió de ser más llamativa en aquellos lugares donde los incendios y los aprovechamientos fraudulentos fueron moneda corriente, como consecuencia de los "desórdenes" que acontecieron a raíz de la revolución de 1868 y durante la I República. Véanse, al efecto, el cuadro 3 y Zapata (1986a, pp. 477-478). 


\section{CUADRO 3}

Producción de los montes públicos y de los de utilidad pública en porcentajes según tipo de aprovechamiento

(España, 1861-1932)

\begin{tabular}{|c|c|c|c|c|c|c|}
\hline & \multicolumn{3}{|c|}{ Montes públicos } & \multicolumn{3}{|c|}{ Montes de utilidad pública } \\
\hline & Ordinarios & Vecinales & $\begin{array}{l}\text { Extraordi- } \\
\text { narios }\end{array}$ & Ordinarios & Vecinales & $\begin{array}{l}\text { Extraordi- } \\
\text { narios * }\end{array}$ \\
\hline $1861-1862 \ldots \ldots \ldots \ldots \ldots$ & 31,3 & 55,8 & 12,9 & - & - & - \\
\hline $1870-1871 \ldots \ldots \ldots \ldots \ldots$ & 17,3 & 56,6 & 25,7 & - & - & - \\
\hline $1879-1880 \ldots \ldots \ldots \ldots . . .$. & 32,6 & 46,9 & 20,5 & - & - & - \\
\hline $1903 \ldots \ldots \ldots \ldots \ldots \ldots \ldots \ldots$ & - & - & - & 46,0 & 44,2 & 9,8 \\
\hline $1913 \ldots \ldots \ldots \ldots \ldots \ldots \ldots$ & - & - & - & 57,6 & 39,1 & 3,3 \\
\hline $1920 \ldots \ldots \ldots \ldots \ldots \ldots \ldots$ & - & - & - & 68,3 & 26,5 & 5,2 \\
\hline $1924 \ldots \ldots \ldots \ldots \ldots \ldots \ldots$ & 58,9 & 35,6 & 5,5 & - & - & - \\
\hline $1932 \ldots \ldots \ldots \ldots \ldots \ldots \ldots$ & 69,5 & 24,6 & 5,9 & - & - & - \\
\hline
\end{tabular}

* La mayor parte de los aprovechamientos extraordinarios eran fraudulentos.

FuENTES: Los cálculos se han verificado sobre GEHR (1991, cuadros 17 y 19), Dirección General de Agricultura, Minas y Montes (1915, pp. LII-LIII), Dirección General de Agricultura, Minas y Montes (1922, pp. XXXIII-XXXIV), Dirección General de Agricultura y Montes (1926, p. 30), y Dirección General de Montes, Pesca y Caza (1934, p. 29).

\section{CUADRO 4}

Aprovechamientos forestales en los montes ordenados (España, 1902-1920)

\begin{tabular}{|c|c|c|c|c|c|c|}
\hline & \multicolumn{3}{|c|}{ Miles de pesetas corrientes } & \multicolumn{3}{|c|}{$\begin{array}{c}\text { Porcentaje sobre el total } \\
\text { de cada año }\end{array}$} \\
\hline & Ordinarios & Vecinales & $\begin{array}{l}\text { Extraordi- } \\
\text { narios }\end{array}$ & Ordinarios & Vecinales & $\begin{array}{c}\text { Extraordi- } \\
\text { narios }\end{array}$ \\
\hline $1902-1903 \ldots \ldots \ldots \ldots \ldots$ & 846 & 76 & 106 & 82,3 & 7,4 & 10,3 \\
\hline $1912-1913 \ldots \ldots \ldots \ldots \ldots$ & 3.117 & 360 & 183 & 85,2 & 9,8 & 5,0 \\
\hline $1919-1920 \ldots \ldots \ldots \ldots \ldots$ & 4.424 & 297 & 320 & 87,8 & 5,9 & 6,3 \\
\hline
\end{tabular}

FUENTES: Dirección General de Agricultura, Industria y Comercio (1907), y Dirección General de Agricultura, Minas y Montes (1915) y (1922). 


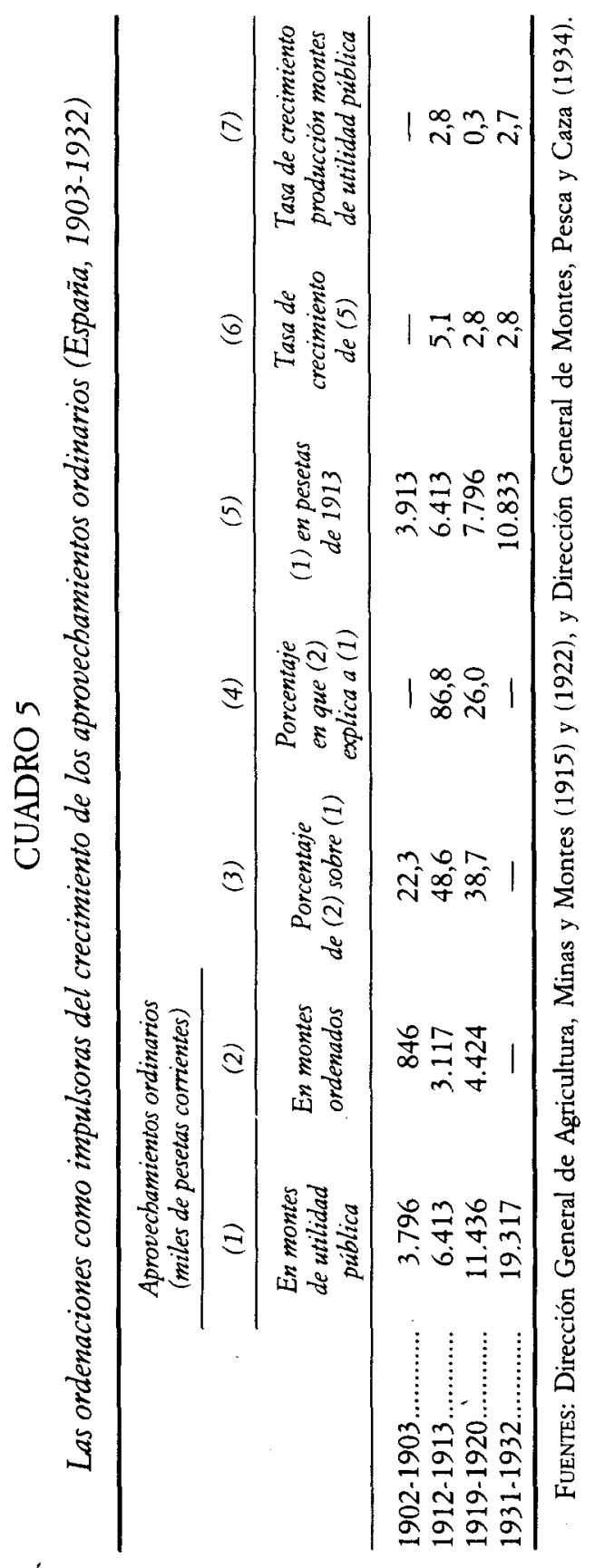


la producción son siempre mucho mayores que los de las superficies correspondientes ${ }^{14}$.

Dichas ordenaciones, que se consideraban como «el fin supremo a que debe aspirarse en el tratamiento de la riqueza forestal» ${ }^{15}$, ponen de manifiesto, en esta tercera etapa, una intensificación de la intervención del Estado. No obstante, sus consecuencias fueron muy desiguales en el espacio, ya que, pese a su continuo incremento, sólo afectaron a una reducida superficie - como indica el cuadro 6-, concentrada en muy pocas provincias y en los aprovechamientos más mercantilizados —-madera, resina y corcho-, a tenor del parco conocimiento que tenemos de su fase inicial, que se prolongaría, aproximadamente, hasta el fin de la I Guerra Mundial, en la que, según parece, ejerció una influencia decisiva la iniciativa privada ${ }^{16}$.

\section{CUADRO 6}

Superficie y producción de los montes ordenados y de los repoblados en porcentajes de las correspondientes de los montes de utilidad pública (España, 1903-1932)

\begin{tabular}{|c|c|c|c|c|}
\hline & \multicolumn{2}{|c|}{ Montes ordenados } & \multicolumn{2}{|c|}{ Montes repoblados } \\
\hline & Superficie & Producción & Superficie & Producción \\
\hline 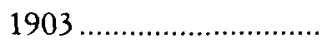 & 2,8 & 12,3 & 0,9 & 0,2 \\
\hline 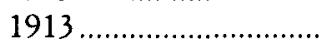 & 8,5 & 32,3 & 2,4 & 1,1 \\
\hline $1920 \ldots \ldots \ldots \ldots \ldots \ldots \ldots \ldots \ldots$ & 8,8 & 28,3 & 2,8 & 1,4 \\
\hline 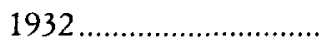 & 11,3 & 38,0 & 4,0 & 2,1 \\
\hline
\end{tabular}

Fuentes: Los cálculos se han hecho sobre GEHR (1991, cuadros 16 y 19).

${ }^{14}$ La expansión de los aprovechamientos ordinarios obedeció a muy diversos motivos, aunque aquí pongamos el énfasis, quizá exagerando, en las ordenaciones. Así, la inflación causada por la I Guerra Mundial, por ejemplo, hizo que, en esos años, los precios de remate de las subastas se quedaran lejos de un índice general de precios en constante y veloz aumento, lo cual debió de atraer a los particulares a las subastas y, en consecuencia, creó una situación favorable para el incremento de los aprovechamientos ordinarios y la disminución de los vecinales.

${ }_{15}$ Exposición de Motivos de la Ley de 9 de mayo de 1890, según la cita Gómez Mendoza (1992, p. 219).

${ }_{16}$ Aunque existen monografías de algunos montes ordenados, como las que figuran en el capítulo 2 de Madrigal (coord.) (1999), todavía no se ha realizado ningún estudio económico de los trabajos de ordenación llevados a cabo en el conjunto de los montes públicos españoles durante el primer tercio del siglo $\mathrm{xx}$. Sobre los aspectos legales y doctrinales de la ordenación, véase Gómez Mendoza (1992, pp. 219-234). En cuanto a la participación de los particulares en las ordenaciones de los montes públicos, el mismo Servicio 


\section{CUADRO 7}

Participación de dos conjuntos de provincias en la superficie

y en la producción de los montes públicos señalados (1912-1913).

Porcentajes sobre el total nacional respectivo

\begin{tabular}{lccccc}
\hline & \multicolumn{2}{c}{ Superficie } & \multicolumn{2}{c}{ Producción } \\
\cline { 2 - 6 } & $\begin{array}{c}\text { De utilidad } \\
\text { pública }\end{array}$ & Ordenados & $\begin{array}{c}\text { De utilidad } \\
\text { pública }\end{array}$ & Ordenados & $\begin{array}{c}\text { Aprovechamientos } \\
\text { ordinarios }\end{array}$ \\
\hline Conjunto 1........ & 32,6 & 9,1 & 21,5 & 7,0 & 5,3 \\
Conjunto 2....... & 9,2 & 61,7 & 31,4 & 33,4 & 70,3 \\
\hline
\end{tabular}

Conjunto 1: Galicia, Asturias, Cantabria, Burgos, León, Palencia y Zamora.

Conjunto 2: Huelva, Cádiz, Córdoba, Jaén, Cuenca, Segovia y Soria.

FUENTES: GEHR (1991, cuadros 16 y 19).

De manera que, a juzgar por los resultados tan diferentes de los conjuntos 1 y 2 del cuadro 7, parece que en esta tercera etapa el Estado llevó a cabo, al mismo tiempo, dos clases bien distintas de intervención: una, «blanda» y relativamente descentralizada, en la mayor parte de los terrenos públicos (el conjunto 1), donde pervivieron usos forestales tradicionales; y otra, «dura», mucho más intensa y centralizada, en las superficies sujetas a ordenación (el conjunto 2), que implicaban pocas hectáreas, pero que tenían gran repercusión sobre las cifras globales por su elevada productividad, en las cuales tuvo lugar una rápida sustitución de aprovechamientos vecinales por ordinarios.

La cuarta y última etapa se extendería de 1924 a 1936. La elección de la última fecha se justifica fácilmente por el estallido de la Guerra Civil. Por su parte, al año 1924 se ha escogido por ser el de la promulgación del Estatuto Municipal y porque a su alrededor se produjeron diversos acontecimientos que modificaron la intervención estatal en los montes públicos tal y como se venía practicando en el período anterior. Éstos fueron, principalmente, el fin de las ordenaciones por particulares, desde 1918; la recuperación del patrimonio forestal de los pueblos por los ayuntamientos, en aplicación del citado Estatuto Municipal, a partir de $1926{ }^{17}$;

de Montes admitía que se trataba de una práctica frecuente: Ministerio de Fomento (1912, t. 2, p. 308).

${ }^{17}$ Recuérdese que estos montes de los pueblos, que no eran de utilidad pública, fueron administrados por el Ministerio de Hacienda de 1901 a 1921, y por el de Fomento entre 
y el notable incremento de la inversión en repoblaciones, junto al comienzo efectivo de una política hidrológico-forestal ${ }^{18}$. En esta cuarta etapa, como en las anteriores, también se produjeron importantes reformas legislativas, entre las que debe destacarse la creación del Patrimonio Forestal del Estado en 1935, por la trascendencia práctica que tendría después, durante el franquismo.

Cabría interpretar algunas de estas novedades como un debilitamiento relativo de la intervención de la administración central o como un fortalecimiento de los municipios, y algo de esto debió de haber. Sin embargo, el alza continua de los aprovechamientos ordinarios y la correlativa disminución de los usos vecinales, observables en el cuadro 3, apuntan en sentido contrario. En el cuadro 5 puede apreciarse que ambos movimientos tuvieron que ver menos con las producciones de los montes ordenados -que, en cuanto a superficie, siguieron siendo una pequeña minoría--, que con las de la mayor parte de los montes públicos o de utilidad pública, dependientes de los distritos forestales.

$\mathrm{Y}$, asimismo, cabe suponer que en esta última etapa la política forestal alcanzase cierta madurez, al haberse puesto ya en práctica sus principales instrumentos (catálogos, planes, subastas, ordenaciones, repoblaciones y guardería), si bien, en última instancia, las medidas que se aplicaran y los efectos que pudiesen producir dependerían del equilibrio al que se llegase tras el forcejeo permanente que existía entre los actores de dicha política: particulares, vecinos, ayuntamientos y administración central.

No cabe duda de que una mejor comprensión de la política forestal practicada en las etapas señaladas requiere de un estudio detenido de la problemática forestal de las diversas regiones españolas. No obstante, como se dijo en la introducción, esa labor no la vamos a desarrollar aquí.

1922 y 1925 . Y adviértase que la vuelta de dichos montes a la administración municipal, aunque pudo ser consecuencia de la presión de los pueblos, hubo de resultar, también, de la necesidad de la administración central de desembarazarse de un patrimonio de difícil gestión y que otorgaba unos rendimientos muy bajos. ¿Para qué querían los Ministerios de Hacienda o de Fomento los que, seguramente, eran los peores montes públicos de España, de los cuales ni siquiera los declarados enajenables parecian contar con demandantes?

${ }^{18}$ Véase Gómez Mendoza (1992, pp. 235-248). Con respecto a las repoblaciones habidas en esta etapa, hay que decir que afectaron, como en la anterior y al igual que en el caso de las ordenaciones, a una reducida superficie, concentrada en muy pocas provincias, y que su principal objeto fue la fijación del suelo para proteger a las explotaciones agrarias del arrastre de tierra por la acción del agua y de arena por el viento: Ministerio de Fomento (1912, pp. 310-356). 


\section{LAS PRODUCCIONES DE LOS MONTES DE UTILIDAD PÚBLICA}

La evolución seguida por la producción de los montes de utilidad pública proporciona buenas pistas para entender la lógica que guió la política forestal y evaluar sus principales consecuencias, aunque, por lo que llevamos visto, parece probable que la evolución y composición de la citada producción dependiese, en gran medida, del mercado y de decisiones tomadas por agentes distintos a los funcionarios del ramo de montes. En todo caso, debe tenerse en cuenta que los datos que aportan las Estadísticas de la Producción de los Montes Públicos reflejan con distinto grado de veracidad las producciones efectivas, según la forma de gestión del monte, y, dada ésta, según el nivel de control que la administración central tuviera sobre sus aprovechamientos.

La evolución de la producción, en su conjunto, se ha representado en el gráfico 1, y la de los distintos esquilmos, en el gráfico 2. En éste, se ha multiplicado la producción física de cada producto por los valores medios que alcanzó cada uno en las estadísticas del año forestal 1912-1913, por lo que las curvas recogen la trayectoria de la producción en términos de volumen; y en el gráfico 1 se han agregado las cifras del gráfico 2 . Como se observa, la producción total creció de forma continua y regular durante el primer tercio del siglo XX, aunque se aprecia cierto estancamiento en los años de la I Guerra Mundial. La intensidad de dicho crecimiento, con una tasa anual del 2,5 por 100 , resulta superior a la del conjunto del sector agrario español, cuya tasa sólo alcanzó el 1,9 por $100^{19}$.

Este notable crecimiento es indicio de la buena salida comercial de los esquilmos forestales y de una acertada respuesta a los impulsos del mercado de los distintos sujetos que organizaban los aprovechamientos del monte público, aún más cuando es muy probable que la estimación que hacemos de su magnitud quede por debajo de la real ${ }^{20}$.

El gráfico 2 y el cuadro 8 evidencian que los esquilmos protagonistas del crecimiento fueron la madera y la resina, tanto por su intenso ritmo de aumento, como por su relevante peso en el producto total, lo que resulta

19 Las tasas de crecimiento de la producción de los montes públicos se han calculado a partir de GEHR (1989, p. 110, cuadro 3.14). En el caso de la producción agraria, los datos proceden de una estimación del índice de producción agraria (GEHR, 1987, pp. 420-421). En ambos casos, las tasas se han establecido a partir de la producción media, expresada en volumen, de los quinquenios 1903-1907 y 1929-1933.

${ }^{20}$ Sobre las causas generales de la infravaloración de los aprovechamientos, véase GEHR (1991, pp. 72-77). 


\section{GRÁFICO 1}

Producción de los montes de utilidad pública valorada según los precios de 1913 (1901-1933). En miles de pesetas

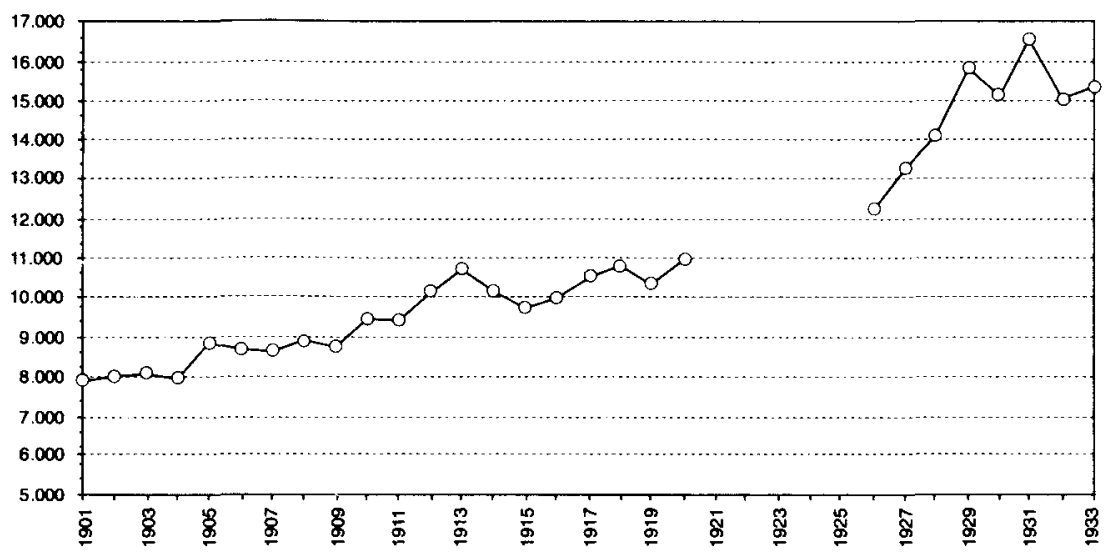

FUENTE: GEHR (1989: 105, 109 y 100, cuadros 3.8, 3.13 y 3.14).

Nota sobre los gráficos 1 y 2: Faltan los datos de 1921, porque no hemos localizado la Estadística correspondiente, y los de 1922 a 1925, porque en tales años los montes dependientes de Hacienda también fueron administrados por el Ministerio de Fomento, y la fuente no permite distinguir las cifras de producción concernientes a los montes de utilidad pública de las referentes a aquéllos. El dato del esparto de 1931, que no aparece en el gráfico 2, es cero. Hemos renunciado en éste a representar la evolución seguida por el corcho, porque sus intensas fluctuaciones impedían apreciar las trayectorias de los demás esquilmos.

coherente con otros testimonios. La madera era una materia prima de la que nuestro país no disponía en cantidad suficiente, como lo demuestra el que la principal partida de las importaciones forestales la integrasen troncos y tablas, cuyo incremento sostenido durante el primer tercio del siglo $\mathrm{xx}$ permite pensar, para tal período, en un mercado interior de madera en constante crecimiento, impulsado por el desarrollo general de la economía española, del que pudieron beneficiarse los usufructuarios del monte público $^{21}$.

El caso de la resina, estudiado por Uriarte (1995a, 1995b, 1996, 1998), remite a la existencia, en diversas zonas del país, de condiciones ecológicas adecuadas para su obtención y a la evolución al alza de la demanda y

${ }^{21}$ Iriarte (1995, pp. 594-702); Zapata (2001). 


\section{GRÁFICO 2}

Producción de los montes de utilidad pública por esquilmos valorada según los precios de 1913 (1901-1933). En miles de pesetas

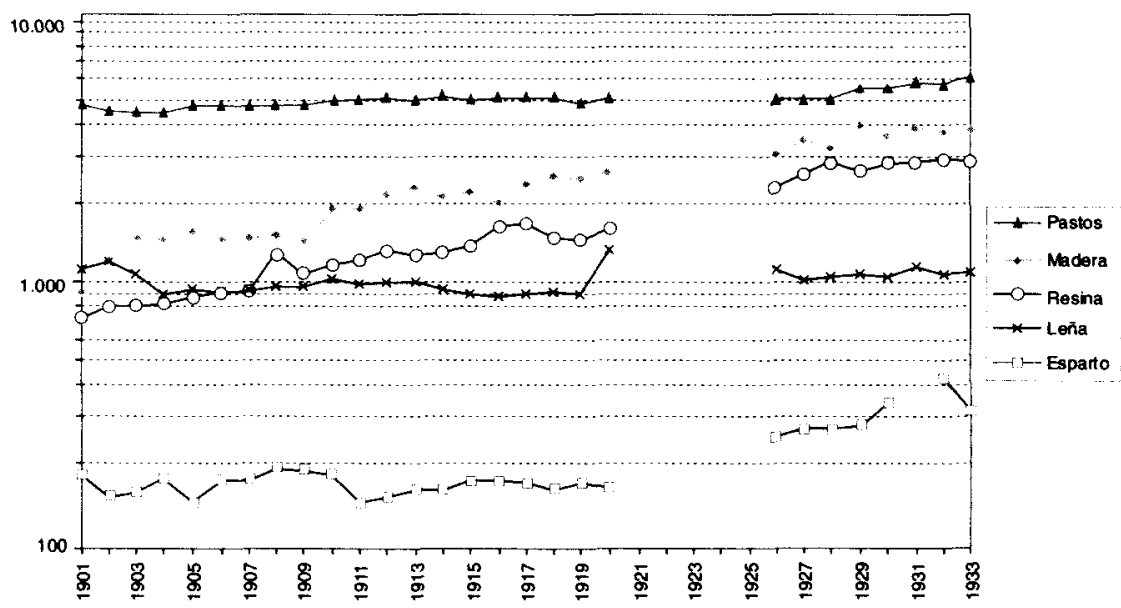

FUENTE: GEHR (1989: 105, 109 y 100, cuadros 3.8, 3.13 y 3.14). (Ver la Nota sobre los gráficos 1 y 2 , que se encuentra bajo el gráfico 1.)

de los precios internacionales de los productos resinosos. A fines del siglo $\mathrm{xIX}$ y en el primer tercio del $\mathrm{xx}$, se fue formando un sector industrial resinero, orientado al mercado interior y a la exportación, parte del cual acabó integrándose en la Unión Resinera Española, que no sólo constituyó su propio patrimonio forestal, sino que también participó en la explotación de los montes públicos y en las ordenaciones.

Los casos del corcho y del esparto son menos relevantes porque, pese a su apreciable expansión, nunca dejaron de suponer una reducida fracción de la producción de los montes públicos ${ }^{22}$. Por ello, nos fijaremos preferentemente en la leña y en los pastos, dos esquilmos cuyas producciones, en términos absolutos, fluctuaron entre el estancamiento y un ligero aumento, perdiendo buena parte de su peso específico en términos relativos. Ello podría explicarse, en lo referente a la leña, por tratarse de un combustible que iba siendo sustituido por otros, aunque quizá dicho proceso de sus-

${ }^{22}$ Sobre la producción y el mercado del corcho, véanse Zapata (1986b) y (1996), Sala (1998a) y Jiménez Blanco (1999), y sobre el caso del esparto, Jiménez Blanco (1986, t. 1, pp. 416-427), 


\section{CUADRO 8}

Producción de los montes de utilidad pública valorada con los precios de 1913 (España, 1901-1933). Medias quinquenales en miles de pesetas

\begin{tabular}{|c|c|c|c|c|c|c|c|c|}
\hline & Madera & Leña & Pastos & Esparto & Resina & $\begin{array}{l}\text { Corcbo y } \\
\text { cortezas }\end{array}$ & Roturaciones & Total \\
\hline & \multicolumn{7}{|c|}{ Producción media anual en miles de pesetas } & \\
\hline $1901-1905 \ldots \ldots .$. & .1 .324 & 1.037 & 4.622 & 160 & 804 & 211 & 0 & 8.157 \\
\hline $1916-1920 \ldots \ldots .$. & .2 .414 & 985 & 5.025 & 165 & 1.568 & 308 & 49 & 10.514 \\
\hline \multirow[t]{2}{*}{$1929-1933 \ldots \ldots}$. & 3.837 & 1.082 & 5.767 & 273 & 2.853 & 1.459 & 296 & 15.567 \\
\hline & \multicolumn{7}{|c|}{ Porcentaje sobre la producción total } & \\
\hline $1901-1905 \ldots \ldots .$. & . 16,5 & 12,7 & 56,7 & 2,0 & 9,9 & 2,6 & 0,0 & 100,0 \\
\hline $1916-1920 \ldots \ldots .$. & . 23,0 & 9,4 & 47,8 & 1,6 & 14,9 & 2,9 & 0,5 & 100,0 \\
\hline \multirow[t]{2}{*}{$1929-1933 \ldots \ldots$} & . 24,7 & 7,0 & 37,0 & 1,8 & 18,3 & 9,4 & 1,9 & 100,0 \\
\hline & \multicolumn{7}{|c|}{$\begin{array}{l}\text { Números indices (Base } 100 \text { en 1903-1907, } \\
\text { excepto Roturaciones en 1916-1920) }\end{array}$} & \\
\hline $1901-1905 \ldots \ldots \ldots$ & 100 & 100 & 100 & 100 & 100 & 100 & - & 100 \\
\hline $1916-1920 \ldots \ldots .$. & 182 & 95 & 109 & 103 & 195 & 146 & 100 & 129 \\
\hline $1929-1933 \ldots \ldots$. & 290 & 104 & 125 & 171 & 355 & 691 & 407 & 191 \\
\hline
\end{tabular}

FUENTES: GEHR $(1989,105,109$ y 110 , cuadros $3.8,3.13$ y 3.14$)$.

titución fuese, en el primer tercio del siglo $\mathrm{xx}$, más lento de lo que cabría esperar. Además, hay que señalar que la producción de leña de monte bajo sí disminuyó en términos absolutos, al contrario que la de leña de monte alto, la cual, al ser un subproducto de las explotaciones madereras, conoció un crecimiento persistente, observable en los cuadros 9 y 10.

En cuanto a los aprovechamientos ganaderos, el alza del 25 por 100 que aconteció durante el primer tercio del siglo XX es la de menor intensidad de las registradas por los productos considerados, si se prescinde de la leña, situándose muy por debajo del 42 por 100 , incremento éste que, para el mismo período, cabe atribuir al peso en vivo de la ganadería española ${ }^{23}$. Semejante resultado es chocante, pues, aun contando con una agricultura más orientada a la producción de piensos y con una mayor disponibilidad de forrajes, parece excesiva la diferencia entre la expansión ganadera y la de los pastos de los montes públicos. Pudo darse, quizá, una mala medición de estos aprovechamientos, a los que se aplicaban «pre-

${ }^{23}$ Gallego (1986, p. 581). 


\section{CUADRO 9}

Producción de los montes de utilidad pública dependientes de la Inspección de Ordenaciones (España, 1901-1920)

\begin{tabular}{|c|c|c|c|c|c|}
\hline & $\begin{array}{l}\text { Madera } \\
\left(\text { miles } m^{3}\right)\end{array}$ & $\begin{array}{c}\text { Leña de } \\
\text { monte alto } \\
\text { (miles estéreos) }\end{array}$ & $\begin{array}{c}\text { Leña de } \\
\text { monte bajo } \\
\text { (miles estéreos) }\end{array}$ & $\begin{array}{l}\text { Peso en vivo } \\
\text { que pasta } \\
\text { (miles Qms.) }\end{array}$ & $\begin{array}{c}\text { Resinas } \\
\text { (miles Qms.) }\end{array}$ \\
\hline & \multicolumn{5}{|c|}{ Producción de los montes ordenados en las unidades indicadas } \\
\hline $1901-1904 \ldots \ldots . .$. & 52 & 19 & 1 & 60 & 59 \\
\hline \multirow[t]{2}{*}{$1918-1920 \ldots \ldots}$. & 143 & 106 & 17 & 284 & 84 \\
\hline & \multicolumn{5}{|c|}{ Números indices con base 100 en 1901-1904 } \\
\hline $1901-1904 \ldots \ldots \ldots$ & 100 & 100 & 100 & 100 & 100 \\
\hline \multirow[t]{2}{*}{$1918-1920 \ldots \ldots}$. & 275 & 558 & 1.700 & 473 & 142 \\
\hline & \multicolumn{5}{|c|}{$\begin{array}{l}\text { Porcentaje respecto a la producción total de cada esquilmo } \\
\text { en los montes de utilidad publica }\end{array}$} \\
\hline $1901-1904 \ldots \ldots . .$. & 37,5 & 7,1 & 0,0 & 2,2 & 70,5 \\
\hline $1918-1920 \ldots \ldots .$. & 50,5 & 22,9 & 1,3 & 9,7 & 61,1 \\
\hline
\end{tabular}

FuENTES: Dirección General de Agricultura, Industria y Comercio (1906a), (1906b), (1907) y (1908), y Dirección General de Agricultura, Minas y Montes (1920), (1921) y (1922), excepto para las resinas, cuyas cifras se han calculado a partir de los datos de rendimientos y de número de pinos que ofrece Uriarte (1995b, 542-546).

cios políticos» ${ }^{24}$, y a ello coadyuvaría el tratarse de un esquilmo poco controlado por la administración, lo que dificultaba la elaboración de la estadística correspondiente.

Sea lo que fuere, lo que no ofrece dudas acerca de la composición de la producción de los montes públicos en el primer tercio del siglo $\mathrm{xx}$, es su creciente carácter forestal en sentido estricto, y ello pese a la probable infravaloración de los pastos. Los productos y subproductos típicamente forestales - madera, leña de monte alto, resina y corcho y cortezas - pasaron de suponer el 32 por 100 de la producción de los montes de utilidad pública en 1901-05, a situarse en el 55,4 por 100 en 1929-33. En cambio, los esquilmos propios del monte bajo - leña de monte bajo, pastos, esparto y roturaciones- bajaron, entre los mismos quinquenios, del 68 por 100 al 45 por 100 del citado producto.

Cabe preguntarse, a continuación, en qué medida puede atribuirse a la acción del Estado esa tendencia a acentuar el carácter forestal de la producción de los montes públicos. Aunque se trate de un asunto que

${ }^{24}$ Véase Zapata (1986a, pp. 503-514). 


\section{CUADRO 10}

Producción de los montes de utilidad pública dependientes de los distritos (España, 1901-1920)

\begin{tabular}{|c|c|c|c|c|c|}
\hline & $\begin{array}{l}\text { Madera } \\
\left(\text { miles } m^{3}\right)\end{array}$ & $\begin{array}{c}\text { Leña de } \\
\text { monte alto } \\
\text { (miles estéreos) }\end{array}$ & $\begin{array}{c}\text { Leña de } \\
\text { monte bajo } \\
\text { (miles estéreos) }\end{array}$ & $\begin{array}{l}\text { Peso en vivo } \\
\text { que pasta } \\
\text { (miles Qms.) }\end{array}$ & $\begin{array}{c}\text { Resinas } \\
\text { (miles Qms.) }\end{array}$ \\
\hline & \multicolumn{5}{|c|}{ Producción de los montes de los distritos en las unidades indicadas } \\
\hline & 87 & 243 & 1.604 & 2.599 & 25 \\
\hline \multirow[t]{2}{*}{$1918-1920 \ldots \ldots$} & 138 & 359 & 1.290 & 2.596 & 54 \\
\hline & \multicolumn{5}{|c|}{ Números indices con base 100 en 1901-1904 } \\
\hline $1901-1904 \ldots \ldots .$. & 100 & 100 & 100 & 100 & 100 \\
\hline \multirow[t]{2}{*}{$1918-1920 \ldots \ldots . .}$. & 157 & 148 & 80 & 100 & 216 \\
\hline & \multicolumn{5}{|c|}{$\begin{array}{l}\text { Porcentaje respecto a la producción total de cada esquilmo } \\
\text { en los montes de utilidad pública }\end{array}$} \\
\hline $1901-1904 \ldots \ldots \ldots$ & 62,8 & 92,9 & 100,0 & 97,6 & 29,5 \\
\hline $1918-1920 \ldots \ldots .$. & 48,7 & 77,1 & 98,7 & 88,9 & 39,2 \\
\hline
\end{tabular}

FUENTES: Dirección General de Agricultura, Industria y Comercio (1906a), (1906b), (1907) y (1908), y Dirección General de Agricultura, Minas y Montes (1920), (1921) y (1922), excepto para las resinas, cuyas cifras se han calculado a partir de los datos de rendimientos y de número de pinos que ofrece Uriarte (1995b, 542-546).

deba analizarse con fuentes distintas de las utilizadas aquí, éstas proporcionan algunas ideas que merece la pena retener.

Si tenemos en cuenta, primero, que la mencionada tendencia, puesta de manifiesto en los cuadros 9 y $10^{25}$, operó tanto en los montes ordenados como en los dependientes de los distritos, centrándose el incremento de la producción, en ambos casos, en la madera y en la resina, y, en segundo lugar, que es probable que los montes de particulares experimentasen cambios semejantes en el mismo período, podría pensarse -y lo proponemos como una hipótesis a verificar con otras fuentes- que el grado y la intensidad con que el Estado intervino en los distintos terrenos forestales no debe considerarse como el elemento explicativo esencial de las variaciones en la cantidad y en la composición de la producción forestal.

Ahora bien, continuamos con nuestra hipótesis, la administración central, con su actividad reguladora, sí que debió de ejercer una influencia decisiva en la selección de quienes podían acceder al disfrute de los distintos

${ }^{25}$ Adviértase que el elevado aumento porcentual de la leña de monte bajo y de los pastos en los montes ordenados se debe al bajísimo nivel absoluto de partida que presentan sendos aprovechamientos. 
tipos de aprovechamientos. De ahí nuestra suposición de que la intervención del Estado en la parte del subsector forestal de titularidad pública afectaría a la trayectoria de la producción, sobre todo de forma indirecta, mediante la autorización a los individuos, comunidades vecinales o empresas que, en cada caso, tuvieran derecho a obtener el producto de que se tratara.

Pero otras circunstancias hubieron de ejercer, con seguridad, una influencia considerable en las formas de explotación de los montes públicos $y$ en las decisiones de los agentes, privados o no, vinculados a las mismas. Nos referimos a la evolución de los mercados de productos forestales, asunto cuya importancia no es preciso ponderar pero del que ignoramos casi todo, por lo que dejaremos los imprescindibles argumentos mercantiles para otro trabajo posterior.

A pesar de todo, puede extraerse alguna información de las fuentes que aquí utilizamos, a partir de las cuales hemos construido los gráficos 3 y 4 .

En el gráfico 3, se comparan el índice general de precios de la economía española y un índice de los valores medios de los esquilmos de los montes de utilidad pública ${ }^{26}$. Está claro que ambos índices recorrieron caminos análogos antes de la I Guerra Mundial, que en el lapso de conflicto bélico el índice forestal se quedó rezagado respecto del índice general y que, desde el comienzo de la postguerra, este último discurrió por debajo de aquél.

Si damos crédito a las reiteradas quejas de los ingenieros sobre la infravaloración de los aprovechamientos de los montes públicos -véase GEHR (1994: mapas 15 a 17) -, cabe afirmar que dicha infravaloración se mantuvo hasta 1914, que aumentó durante la Gran Guerra y que sólo empezó a corregirse en la década de 1920.

El gráfico 4, en el que se han representado los valores medios de diversos aprovechamientos deflactados con el índice general de precios, confirma y, a la vez, matiza lo anterior. Lo confirma, porque las tendencias de los cinco aprovechamientos considerados se ajustan, más o menos, a la del patrón del índice forestal. Y lo matiza, porque tales tendencias difieren mucho entre sí, ya que mientras en unas - las de la madera y la resinaexistió una rápida corrección de la aludida infravaloración, en las demás -las de los pastos, la leña y el esparto- apenas se percibe esa corrección,

${ }^{26} \mathrm{El}$ primero corresponde al resultado de empalmar el índice elaborado por Sardá (1948, pp. 302-305) con el de la Comisión del Patrón Oro (1929) y con el de Alcaide (1976). El segundo lo hemos calculado dividiendo la producción total de los montes de utilidad pública, valorada a precios corrientes, entre la misma producción valorada en todos los años con los precios de 1913. 


\section{GRÁFICO 3}

Indice general de precios e indice de las valoraciones medias de los aprovechamientos de los montes de utilidad pública (1901-1933). Base 100 en 1913

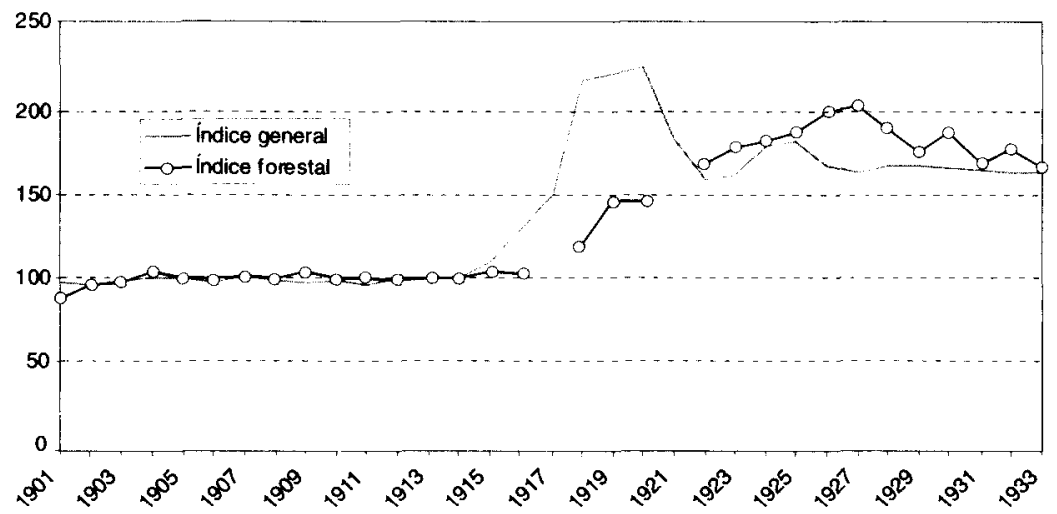

FUENTE: GEHR (1989: 110, cuadro 3.14) y las citadas en la nota 26. (Faltan los datos de 1917 y 1921 porque no hemos localizado las Estadisticas correspondientes.)

de lo que cabe deducir, pese a nuestra ignorancia sobre el tema, que la diversidad fue, sin duda, una de las notas características de los mercados de productos forestales, tanto si eran libres, como si estaban, en el grado que fuese, intervenidos por el Estado.

Sin embargo, el bajo precio relativo de los esquilmos no debió de ser la única forma de apropiación de valor añadido forestal por parte de los beneficiarios de los aprovechamientos de los montes públicos, pues también contarían para ello con la mayor o menor facilidad de obtener unos ingresos extraordinarios --sin duda, fraudulentos-, sacando del monte cantidades superiores a las suscritas en los contratos de los planes, según la atención que los efectivos de la Guardia Civil y de la Guardería Forestal, habitualmente escasos, pudiesen prestar al cumplimiento de lo acordado en los aprovechamientos legales.

Si el bajo precio relativo de los esquilmos y la posibilidad de fraude en sus aprovechamientos hacían, como suponemos, atractiva la explotación del monte público por los particulares, es muy probable que éstos, ya fueran individuos, comunidades vecinales o empresas, presionaran a las adminis- 


\section{GRÁFICO 4}

Valores medios ponderados de los principales aprovechamientos de los montes de utilidad pública (1912-1933). En pesetas constantes de 1913

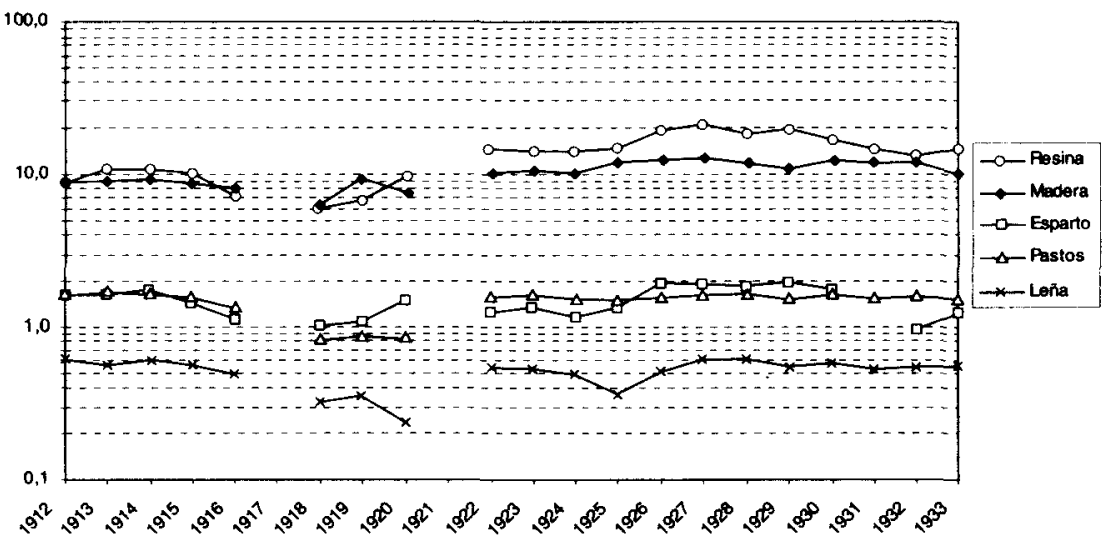

FUENTE: GEHR (1989: 105, 109, y 110, cuadro $3.8,3.13$, y 3.14) y las citadas en la nota 26. (Faltan los datos de 1917 y 1921 porque no hemos localizado las Estadísticas correspondientes.)

traciones gestoras para conseguir un trato de favor. De esta manera, el Estado y los funcionarios que estaban a su servicio, atendiendo a las señales que recibían de los mercados forestales y de la economía y de la sociedad españolas — cuyas evoluciones quedaban fuera de su alcance-, más que valedores del equilibrio entre productividad y protección de los montes públicos, serían los intermediarios de la utilización de estos montes, discriminando de diversa forma el acceso a los mismos.

Los cambios, ya aludidos en páginas anteriores, en la forma de realizar tal mediación por parte del Estado - particularmente los acaecidos en la década de 1920 - y el desarrollo de políticas que implicaban una transformación del monte, deben situarse, también, en el contexto de las fuerzas sociales que actuaban sobre el sector público para que éste diese prioridad a determinados objetivos y formas de alcanzarlos. 


\section{RECAPITULACIÓN FINAL}

Dado lo que aún ignoramos sobre aspectos trascendentales de la política forestal y de la gestión de los montes públicos españoles durante la segunda mitad del siglo Xxx y el primer tercio del $\mathrm{xx}$ —el impacto real de la introducción y generalización de planes de aprovechamiento, las características de la administración de los montes dependientes de Hacienda entre 1901 y 1921, y lo ocurrido con los montes privados y los mercados de productos forestales, por citar los más notables-, sería pretencioso terminar este texto con un apartado de conclusiones. Empero, cabe ordenar un poco el esbozo de marco general que contiene.

En el período de referencia, se constituyó en España un patrimonio forestal público muy extenso, cuya producción, en conjunto, seguramente suponía una porción relevante de la obtenida por el subsector forestal. No obstante, dicho patrimonio contaba con características que le impidieron convertirse, en contra de lo que era de esperar, en una cómoda plataforma de la política forestal del Estado. En efecto, el grado de influencia que permitía ejercer sobre el citado subsector era muy desigual, dada su irregular distribución por el territorio nacional y la dispar importancia, según esquilmos, de sus producciones. Por ello, no era fácil que la administración central impulsase una decidida política de organización del subsector forestal a partir de los montes públicos.

Si a ello se añade que la actuación del Estado debía conjugar elementos tan dispares como, primero, las demandas ejercidas por la economía y la sociedad españolas — canalizadas a través de los mercados de productos forestales, abastecidos en parte por los montes públicos-, segundo, los variados objetivos de los grupos sociales dispuestos a participar en la explotación de los terrenos forestales públicos —entre ellos, los de las localidades y comarcas por las que se extendían éstos, poco homogéneos y con una capacidad muy distinta de influir sobre la administración y sus funcionarios-, tercero, los criterios de sus técnicos acerca de la explotación y la conservación del monte y, cuarto, los intereses de empresas privadas, particulares, comunidades vecinales y ayuntamientos -que eran, junto a la propia administración central, los protagonistas de las diferentes actuaciones-, se comprende que la intervención del Estado sobre los montes públicos tuviese una intensidad muy diversa y respondiera a fines cambiantes.

Al respecto, nuestra hipótesis sobre el desarrollo de la mencionada actuación durante el período estudiado contempla cuatro etapas. La pri- 
mera, entre 1855 y 1875 , en cuyo transcurso la atención del Estado se centró en el colosal proceso de privatización de terrenos forestales que impulsó la desamortización de Madoz, así como en la constitución de un patrimonio forestal público, y apenas en la gestión de éste. La segunda, entre 1875 y 1900, en la cual dicha gestión pasó a primer plano, dotándose la administración central de los primeros instrumentos serios de control de su patrimonio forestal - planes de aprovechamiento y guardería a cargo de la Guardia Civil- y estableciendo sus principales líneas de actuación -ordenaciones y repoblaciones-. La tercera, entre 1900 y 1924, iniciada con la importante novedad que supuso la división de los montes públicos en dos subconjuntos - los de utilidad pública, confiados al Ministerio de Fomento, y los dependientes del Ministerio de Hacienda-, en la que parece que se consolidó lo que se insinuaba en la anterior, mediante la efectiva puesta en marcha de las repoblaciones y de las ordenaciones de un número creciente de montes de utilidad pública, el afianzamiento de los aprovechamientos ordinarios frente a los vecinales y, en general, una intensificación de la intervención del Estado. Ésta, sin embargo, parece que se atuvo a dos pautas distintas: una, relativamente descentralizada y con un encauzamiento de la producción hacia esquilmos de escasa vocación forestal en sentido estricto, aplicada a la mayor parte de los terrenos, donde pervivieron los usos tradicionales vinculados a los aprovechamientos vecinales; y otra, más centralizada y con una intensa orientación hacia los aprovechamientos más ligados a las industrias forestales, en los espacios sometidos a ordenación, donde el progreso de los aprovechamientos ordinarios fue más rápido. Por último, la cuarta etapa, entre 1924 y 1936, en la que la política forestal parece adquirir cierta madurez, una vez en marcha sus principales instrumentos, con medidas significativas como la prohibición de que los particulares efectuasen ordenaciones, ya desde 1918, el importante avance de las repoblaciones, el inicio de una política hidrológico-forestal e, incluso, la devolución a los pueblos de los antiguos montes de Hacienda.

El estudio de la producción de los montes de utilidad pública entre 1901 y 1933 permite acercarse a los móviles que guiaron la política forestal y evaluar sus principales consecuencias. Dos hechos destacan sobre cualquier otro: el aumento continuo y regular -mayor que el registrado por el conjunto del sector agrario- de la citada producción durante dicho período; y el creciente protagonismo que, en el seno de la misma, tuvieron los productos del monte alto - madera y resina, especialmente - frente a los esquilmos propios del monte bajo - pastos y leña, fundamentalmen- 
te-. En cuanto a qué cuota de responsabilidad tuvo la acción del Estado en semejante trayectoria, si bien las fuentes que aquí utilizamos no son las más adecuadas para establecerla, nos inclinamos por una mayor importancia de su acción reguladora e indirecta - de selección de quienes podían acceder al disfrute de los diversos aprovechamientos de los montes públicos-, que de su acción directa, persiguiendo la acentuación del carácter forestal de tal producción. Al fin y a la postre, la tendencia a que el crecimiento del producto se centrase en la madera y la resina se aprecia lo mismo en los montes ordenados que en los dependientes de los distritos $y$, probablemente, aunque de éstos apenas sabemos nada, en los montes de particulares. No obstante, esta hipótesis, como otros extremos apuntados, queda pendiente de verificación.

En suma, también los montes públicos estarían respondiendo a los requerimientos de los mercados de productos forestales y, es de suponer, dado el bajo coste relativo del acceso a sus esquilmos y las posibilidades de fraude en el volumen de los aprovechamientos, que lo hicieron en condiciones de atraer a muchos particulares. En este punto, el Estado y sus funcionarios ejercieron, en nuestra opinión, una labor fundamental de intermediación, de discriminación en el acceso a los mismos.

\section{APÉNDICE}

\section{Glosario de términos forestales españoles}

Sólo se incluyen los términos empleados con más frecuencia en el artículo, que, para su identificación, aparecen en cursivas.

\section{TIPOS DE MONTES PÚBLICOS}

Los montes públicos españoles eran los terrenos forestales que pertenecían al Estado, a los ayuntamientos o a otras instituciones de carácter público. En 1901 fueron divididos en dos grupos:

- La mayor parte de los montes públicos recibieron la nueva denominación de montes de utilidad pública. Se trataba de los terrenos que era necesario mantener con arbolado o repoblar, ya que, por su situación, extensión o características del suelo, ejercían una notable influencia en el entorno natural donde se encontraban.

- Una pequeña parte de los montes públicos comenzó a ser llamada montes de Hacienda, debido a que estos montes pasaron a ser administrados por el Ministerio de Hacienda. 


\section{INSTTTUCIONES GESTORAS DE LOS MONTES PÚBLICOS}

Durante el último tercio del siglo Xxx, todos los montes públicos eran gestionados por el Ministerio de Fomento. Con este fin, España estaba dividida en distritos, cuyas superficies coincidian en casi todos los casos con los límites administrativos de las provincias.

Cuando, en 1901, se produjo la división de los montes públicos en montes de utilidad pública y montes de Hacienda, sólo estos últimos dejaron de depender del Ministerio de Fomento y fueron administrados por el Ministerio de Hacienda hasta 1921, por el Ministerio de Fomento entre 1922 y 1925, y por los ayuntamientos desde 1926 en adelante.

En cambio, los montes de utilidad pública permanecieron en el Ministerio de Fomento, aunque su gestión se fue haciendo más compleja y aparecieron nuevas instituciones. Se crearon la Inspección de Ordenaciones y el Servicio de Repoblaciones, para encargarse, la primera, de los montes ordenados, y la segunda, de los montes sometidos a repoblación. Y el resto de los montes de utilidad pública continuaron siendo gestionados por los distritos, por lo cual, a veces, se les conoce como montes de los distritos. De esta manera, la suma de los montes ordenados, más los montes sometidos a repoblación, más los montes de los distritos es igual al conjunto de los montes de utilidad pública.

\section{APROVECHAMIENTOS EN LOS MONTES PÚBLICOS}

En los montes públicos españoles, los aprovechamientos se realizaban con arreglo al plan de aprovechamiento redactado por las autoridades responsables de cada distrito forestal, o de la Inspección de Ordenaciones o del Servicio de Repoblaciones. En los planes de aprovechamiento, se distinguían dos tipos de aprovechamientos:

- Los aprovecbamientos ordinarios, que salían a subasta pública y eran adjudicados al mejor postor.

- Los aprovechamientos vecinales, que no salían a subasta pública, sino que los llevaban a cabo los vecinos de los pueblos donde estaban los montes, de forma gratuita o pagando un precio inferior al de mercado.

Además de estos dos tipos de aprovechamientos previstos en el plan, podían existir otros aprovechamientos extraordinarios o imprevistos, procedentes de los restos dejados por los derribos del viento, por los incendios o por los aprovechamientos fraudulentos.

\section{BIBLIOGRAFIA Y FUENTES}

ALCAIDE INCHAUSTI, Julio (1976): «Una revisión urgente de la serie de renta nacional española en el siglo XIX», en Datos básicos para la bistoria financiera de España, 1850-1975, Madrid, Instituto de Estudios Fiscales, pp. 1125-1150. 
ARAQUe JimÉnEZ, Eduardo (1997): Privatización y agresiones a los montes públicos jiennenses durante la segunda mitad del siglo XIX, Jaén, Diputación Provincial de Jaén.

Artiaga Rego, Aurora, y Balboa López, Xesús (1992): «La individualización de la propiedad colectiva: aproximación e interpretación del proceso en los montes vecinales de Galicia», Agricultura y Sociedad, núm. 65, pp. 101-120.

Balboa López, Xesús (1990): O monte en Galicia, Vigo, Gerais de Galicia.

- (1999): «La historia de los montes públicos españoles (1812-1936): un balance y algunas propuestas», Historia Agraria, núm. 18, pp. 95-128.

Cobo Romero, Francisco; Cruz Artacho, Salvador; y Gonzalez de Molina, Manuel (1992a): «Privatización del monte y protesta campesina en Andalucía oriental», Agricultura y Sociedad, núm. 65, pp. 253-302.

- (1992a): «Privatización del monte y protesta social. Un aspecto desconocido del movimiento campesino andaluz (1836-1920)», Revista de Estudios Regionales, núm. 32, pp. 155-186.

Comisión del Patrón Oro (1929): «Dictamen de la Comisión nombrada por Real Orden de 9 de enero de 1929, para el estudio de la implantación del patrón de oro», Información Comercial Española, núm. 318, 1960, pp. 73-74.

Dirección General de Agricultura, Industria y Comercio (1906a): Estadística de la producción de los montes de utilidad pública, correspondiente al año forestal de 1900-1901, Madrid.

- (1906b): Estadística de la producción de los montes de utilidad pública, correspondiente al año forestal de 1901-1902, Madrid.

- (1907): Estadística general de la producción de los montes de utilidad pública, correspondiente al año forestal de 1902-1903, Madrid.

- (1908): Estadística general de la producción de los montes de utilidad pública, correspondiente al año forestal de 1903-1904, Madrid.

Dirección de Agricultura, Minas y Montes (1915): Estadística general de la producción de los montes de utilidad pública, correspondiente al año forestal de 1912-1913, Madrid.

- (1920): Memoria sobre la estadística general de la producción de los montes de utilidad pública, correspondiente al año forestal de 1917-1918, Madrid.

- (1921): Memoria sobre la estadística general de la producción de los montes de utilidad pública, correspondiente al año forestal de 1918-1919, Madrid.

- (1922): Memoria sobre la estadística general de la producción de los montes de utilidad pública, correspondiente al año forestal de 1919-1920, Madrid.

DiReCCIÓN DE AgRtCultura y MonTes (1926): Estadística general de la producción de los montes públicos y apéndices a la misma, correspondiente al año forestal de 1923-1924, Madrid.

Dirección General de Montes, Pesca y Caza (1934): Estadística general de la producción de los montes públicos y apéndices a la misma, correspondiente al año forestal de 1931-1932, Madrid.

Gallego Martínez, Domingo (1986): La producción agraria de Álava, Navarra y La Rioja, desde mediados del siglo XIX a 1935, Madrid, Universidad Complutense de Madrid, 2 volúmenes.

Gómez MendozA, Josefina (1992): Ciencia y política de los montes españoles (1848-1936), Madrid, ICONA. 
Grupo de Estudios de Historia RuRAL (1987): «Un indice de la producción agraria española, 1891-1935», Hacienda Pública Española, núm. 108-109, pp. 411-422.

- (1989): «El sector agrario hasta 1935», en Albert Carreras (coord.), Estadísticas bistóricas de España. Siglos XIX.XX, Madrid, Fundación Banco Exterior, pp. 91-129.

- (1991): Estadísticas bistóricas de la producción agraria española, 1859-1935, Madrid, Ministerio de Agricultura, Pesca y Alimentación.

- (1994): «Más allá de la "propiedad perfecta". El proceso de privatización de los montes públicos españoles (1859-1926)», Noticiario de Historia Agraria, núm. 8, pp. 99-152.

- (1999): «Diversidad dentro de un orden. Privatización, producción forestal y represión en los montes públicos españoles, 1859-1926», Historia Agraria, núm. 18, pp. 129-178.

IRIARTE GONI, Iñaki (1992): «Una aproximación histórica a las formas de privatización del monte público en Navarra», Agricultura y Sociedad, núm. 65, pp. 175-216.

- (1995): Privatización, particularización y gestión de los montes públicos. Navarra, 1855-1935, Zaragoza, Universidad de Zaragoza, Facultad de Filosofía y Letras (Tesis doctoral).

- (1997): Bienes comunales y capitalismo agrario en Navarra, 1855-1935, Madrid, Ministerio de Agricultura, Pesca y Alimentación.

JimÉnez BlanCo, José Ignacio (1986): La producción agraria de Andalucia oriental, 1874-1914, Madrid, Universidad Complutense de Madrid, 2 vols.

- (1991a): «Los montes de propiedad pública (1833-1936)», en F. Comín Comín y P. Martín Aceña (dirs.), Historia de la empresa pública en España, Madrid, Espasa-Calpe, pp. 241-281.

- (1991b): «Los montes públicos en la España contemporánea: la cara oculta de la propiedad», Noticiario de Historia Agraria, núm. 2, pp. 27-34.

- (1994): «Presente y pasado del monte mediterráneo en España», en A. SáNCHEZ Picón (ed.), Agriculturas mediterráneas y mundo campesino. Cambios históricos y retos actuales, Almería, Instituto de Estudios Almerienses y Diputación de Almería, pp. 111-134.

- (1996): Privatización y apropiación de tierras municipales en la Baja Andalucia: Jerez de la Frontera, 1750-1995, Jerez de la Frontera, Ayuntamiento de Jerez de la Frontera.

- (1999): «La oferta de corcho de los montes públicos españoles, 1900-1933», en A. Parejo Barranco y A. Sánchez Picón (eds.), Economia andaluza e bistoria industrial. Estudios en bomenje a Jordi Nadal, Granada, Asukaria Mediterránea, pp. 375-394.

LINARES LuJÁN, Antonio M. (2001): «Estado, comunidad y mercado en los montes municipales extremeños (1855-1924)», Revista de Historia Económica, núm. 1, pp. 17-52.

López Estudillo, Antonio (1992): «Los montes públicos y las diversas vías de su privatización en el siglo XIX», Agricultura y Sociedad, núm. 65, pp. 65-99.

Madrigal Collazo, Alberto (coord.) (1999): Ciencias y técnicas forestales. 150 años de aportaciones de los ingenieros de montes, Madrid, Fundación Conde del Valle de Salazar. 
Mangas Navas, José M. (1981): El régimen comunal agrario de los concejos de Castilla, Madrid, Ministerio de Agricultura.

- (1984): La propiedad de la tierra en España: los patrimonios públicos. Herencia contemporánea de un reformismo inconcluso, Madrid, Instituto de Estudios Agrarios, Pesqueros y Alimentarios.

Manuel Valdés, Carlos M. (1996): Tierras y montes públicos en la sierra de Madrid (Sectores central y meridional), Madrid, Ministerio de Agricultura, Pesca y Alimentación.

Ministerio de Agricultura (1949): Estadistica Forestal de España. Año 1946-47, Madrid.

Ministerio de Fomento (1912): Memoria relativa a los servicios de la Dirección General de Agricultura, Minas y Montes, Madrid, 2 volúmenes.

Montiel Molina, Cristina (1990): Los montes de utilidad pública en la provincia de Alicante, Alicante, Universidad de Alicante.

- (1992): «Titularidad y régimen de aprovechamiento de los montes catalogados en la Comunidad Valenciana», Agricultura y Sociedad, núm. 65, pp. 389-413.

- (1995): Los montes de utilidad pública en la Comunidad Valenciana, Madrid, Ministerio de Agricultura, Pesca y Alimentación.

MoRENo FERnÁNDEZ, José R. (1994): El monte público en La Rioja durante los siglos XVII y XIX: aproximación a la desarticulación del régimen comunal, Zaragoza, Gobierno de La Rioja.

Pinilla NAVARRo, Vicente (1995): Entre la inercia y el cambio. El sector agrario aragonés, 1850-1935, Madrid, Ministerio de Agricultura, Pesca y Alimentación.

Plan de aprovechamientos para el año forestal de 1920-1921 de los montes públicos a cargo del Ministerio de Hacienda, 1921, Biblioteca del Ministerio de Hacienda, libros 23.469 y 23.470.

Sabio AlCuTÉn, Alberto (1997): Los montes públicos en Huesca (1859-1930). El bosque no se improvisa, Huesca, Diputación Provincial de Huesca.

SALA, Pere (1997): «Conflictividad rural en el monte comunal gerundense: pueblos y mansos ante el Estado interventor en la segunda mitad del siglo XIX», Noticiario de Historia Agraria, núm. 13, pp. 105-124.

- (1998a): «Obrador, indústria i aranzels al districte surer català (1830-1930), Recerques, núm. 37, pp. 109-136.

- (1998b): Sobre la compatibilitat entre bosc productor i bosc protector. (La Catalunya forestal buimida entre la societat agrària i la societat industrial, 1850-1930), Barcelona, Universitat Autònoma de Barcelona, Facultat de Ciències Econòmiques i Empresarials.

SANZ FERNÁNDEZ, Jesús (1985): «La historia contemporánea de los montes públicos españoles, 1812-1930. Notas y reflexiones (I)», en R. Garrabou y J. Sanz (eds.), Historia agraria de la España contemporánea 2. Expansión y crisis (1850-1900), Barcelona, Crítica, pp. 193-228.

- (1986): «La historia contemporánea de los montes públicos españoles, 1812-1930. Notas y reflexiones (II)», en R. Garrabou, C. Barciela y J. I. JIMÉNEz Blanco (eds.), Historia agraria de la España contemporánea 3. El fin de la agricultura tradicional (1900-1960), Barcelona, Crítica, pp. 142-170.

SARDÁ, Juan (1948): La política monetaria y las fluctuaciones de la economía española en el siglo XIX, Madrid, CSIC. 
URUARTE AYo, Rafael (1995a): «La industria resinera española y el mercado internacional. Segunda mitad del XIX», Siglo XIX. Cuadernos de Historia, núm. 13, pp. 65-81.

- (1995b): «La industrialización del bosque en la España interior: producción y cambio técnico en la industria resinera (1860-1914)», Revista de Historia Económica, núm. 3, pp. 509-551.

- (1996): La Unión Resinera Española (1898-1936), Madrid, Fundación Empresa Pública (Documento de Trabajo 9610).

- (1998): «Coyuntura económica y estrategia empresarial: La Unión Resinera Española, 1898-1936», Revista de Historia Industrial, núm. 14, pp. 83-124.

ZAPATA BLANCO, Santiago (1986a): La producción agraria de Extremadura y Andalucía occidental, 1875-1935, Madrid, Universidad Complutense de Madrid, 2 volúmenes.

- (1986b): «El alcornoque y el corcho en España, 1850-1935», en R. GarRabOU, C. Barciela y J. I. Jiménez Blanco (eds.), Historia agraria de la España contemporánea 3. El fin de la agricultura tradicional (1900-1960), Barcelona, Crítica, pp. 230-279.

- (1996): «Corcho extremeño y andaluz, tapones gerundenses», Revista de Historia Industrial, núm. 10, pp. 37-68.

- (2001): «La madera en España (c. 1850-c. 1950). Un primer esbozo», Revista de Historia Económica, núm. 2, pp. 287-343. 